Revista Iberoamericana, Vol. LXIX, Núm. 203, Abril-Junio 2003, 343-353

\title{
APOGEO Y DECADENCIA DE LA TEORÍA TRADICIONAL UNA VISIÓN DESDE LOS INTERSTICIOS ${ }^{1}$
}

\author{
POR \\ SAnTiago CASTRo-Gómez \\ Universidad Javeriana / Instituto Pensar
}

El libro de Carlos Reynoso titulado Apogeo y decadencia de los estudios culturales. Una visión antropológica, publicado en julio del año 2000 por la editorial Gedisa de Barcelona constituye, sin lugar a dudas, un desafío y un estímulo para la práctica teórica de los estudios culturales en América Latina. Es uno de esos libros sobre los que, parodiando la frase de Rodó, puedo decir con certeza que "lo admiro pero no lo amo". Lo admiro por su capacidad de sospecha, por su tono irónico y penetrante, y por ser además un libro escrito con "pasión y sangre”, así como deben ser asumidas las cosas fundamentales en las que creemos. Pero no lo amo porque su autor parece reclamar la obtención de una victoria personal sobre un enemigo de paja, antes que la clarificación de un problema científico. Como tendré oportunidad de demostrar, el libro apela a un modelo de cientificidad - la "teoría tradicional”- que tuvo su apogeo entre los siglos XIX y xx y ahora se encuentra en franca decadencia, por lo que, lejos de impulsar el quehacer de las ciencias sociales contemporáneas, se ha convertido en su mayor estorbo. La admiración, el desamor y la pasión fueron, entonces, los móviles que impulsaron la redacción de este artículo.

A continuación entablaré un diálogo crítico con Reynoso, centrándome básicamente en dos de los temas planteados en el libro. Formularé los temas utilizando las mismas preguntas lanzadas por el autor:

1) ¿̇Ha habido algún asomo de creación teórica en el interior de los estudios culturales, o viven ellos de la depredación de metodologías ocasionales tomadas de las tradiciones científicas de las que reniegan?

2) ¿Constituyen los estudios culturales una antidisciplina o reproducen los cánones disciplinares de la ciencia normal?

Al igual que Reynoso, el marco desde el cual ofrezco responder a estas preguntas es el de la epistemología de las ciencias sociales; pero a diferencia de él, y como participante de esta práctica intersticial denominada “estudios culturales”, mi postura favorecerá los respectivos primeros hemistiquios de las preguntas. Con todo, mi estrategia no consistirá

\footnotetext{
${ }^{1}$ Este artículo fue publicado en Fronteras de la Historia 6 (2001): 191-201.
} 
en oponerme directamente (vis-á-vis) a los argumentos del antropólogo argentino, sino en entablar un diálogo con ellos, entendiendo que muchas de sus críticas a los estudios culturales son, en líneas generales, correctas.

\section{LA INVENCIÓN DEL DIABLO}

Reynoso comienza su texto constatando con horror el crecimiento espectacular de los estudios culturales en la academia anglosajona y también en América Latina durante la última década del siglo xx. Ellos encarnan, en su concepto, "el último grito de la moda" teórica en ambos lados del Atlántico (9). Acude a las dos bases de datos principales en humanidades y ciencias sociales (WorldCat y ERIC) para mostrar que tan solo entre 1996 y 1998 se registraron 654 títulos bajo la rúbrica "Estudios Culturales” (10). El "boom” editorial de los estudios culturales parece incontenible. Su tasa de crecimiento no sólo supera al de todas las demás ciencias sociales juntas, sino que en ninguna parte se percibe una corriente de pensamiento que pueda ofrecerles resistencia. Son más y más las universidades y los institutos de investigación en todo el mundo que incluyen a los estudios culturales dentro de su oferta curricular. ¿A qué se debe este éxito insuperable? La respuesta de Reynoso es inicialmente negativa: el éxito de los estudios culturales no tiene nada que ver con su calidad científica, sencillamente porque no han realizado ningún aporte, ni metodológico ni epistemológico, al avance sustantivo del conocimiento en el campo de las ciencias sociales.

Acudiendo directamente a citas tomadas de los que él considera "representantes canónicos” de los estudios culturales, Reynoso muestra que éstos adolecen de una gravísima debilidad teórica. La creatividad metodológica y epistemológica de los estudios culturales es prácticamente nula debido a dos factores centrales. En primer lugar, y siguiendo el famoso dictum de Marx, los estudios culturales han dado prioridad a la praxis sobre la teoría, subordinando ésta a las necesidades de aquella; en segundo lugar, y en consecuencia de lo anterior, los estudios culturales se han limitado a "depredar" perezosamente los logros metodológicos de las disciplinas tradicionales, considerando (ingenuamente) que la simple agregación pragmática de diferentes marcos conceptuales representa, por sí misma, un progreso en el quehacer teórico de las ciencias sociales. Examinemos de cerca estos dos argumentos.

Los estudios culturales acentuaron siempre la dimensión política del conocimiento. Así por ejemplo, Stuart Hall afirmaba que los estudios culturales no eran otra cosa que la continuación de la política por otros medios; Alan O’Connor decía que los estudios culturales no son una tradición de erudición académica sino una empresa de compromiso político; y Lawrence Grossberg admitía que "los estudios culturales se rehusan a definir su propia adecuación teórica en términos académicos o estrechamente epistemológicos” (167; 83). A partir de estos testimonios, Reynoso concluye que los estudios culturales manejan una imagen romántica y sobredimensionada de sí mismos según la cual, su función social no es tanto producir conocimientos cuanto transformar el mundo. La ciencia debe subordinarse a la política. Es decir que el valor de la ciencia no se mide en términos científico-metodológicos sino en términos político-prácticos. El papel de las 
ciencias sociales sería “intervenir” activamente en la vida pública mediante la producción de intelectuales orgánicos (173).

Ahora bien, para Reynoso las consecuencias de esta infravaloración de la ciencia con respecto a la política no pueden ser otras que el triunfo del oscurantismo y la muerte de la racionalidad crítica. Los estudios culturales no son los impulsores privilegiados de un nuevo paradigma de las ciencias sociales, sino sus mayores enemigos. ${ }^{2}$ Lo que predomina en los estudios culturales es un eclecticismo barato $^{3}$ en el que diferentes teorías se mezclan sin elaborar y cuyo resultado no tiene más sustento que su habilidad para "flotar en el aire" (87). No hay en los estudios culturales ningún aporte conceptual específico al acervo común de las ciencias sociales.

La posición de Reynoso es clara: antes que verdaderos productores de conocimiento, los estudios culturales no son otra cosa que una "gimnasia extravagante de resemantización compulsiva” (81). Para legitimar de algún modo su fachada científica, los estudios culturales se apropian de teorías y métodos provenientes de la antropología, la sociología, la lingüística, la crítica literaria, la filosofía y la ciencia política. Pero con toda esta materia prima lo único que logran coser es una monstruosa colcha de retazos, desprovista de la más mínima rigurosidad metodológica. Y lo que es peor: la debilidad teórica pretende ocultarse bajo la pirotecnia del lenguaje y la sofisticación retórica. Es el caso de teóricos afiliados al poscolonialismo como Gayatri Spivak y Homi Bhabha, quienes apelan a una jerga figurativa y a una sintaxis enredada para presentar en público sus aparentemente "novedosas" teorías. Irremediablemente adictos a la oscura retórica de Lacan y Derrida, los dos pensadores indios — ¡ambos curiosamente profesores de inglés! — torturan a sus lectores con una "jerga marciana” que además se jacta de ser progresista y de situarse junto a los sectores subalternos (117). Para Reynoso, resulta imposible encontrar en esta “jeringonza” algún vestigio de rigor teórico o forma de pensar innovadora, sino tan solo "un arrebato de abstracciones inexpertas, casi ideográficas en vez de analíticas” (119).

\footnotetext{
${ }^{2}$ En otro lugar, Reynoso anota con ironía — por no decir con malicia — que uno de los más señeros antropólogos posmodernos, el norteamericano Michael Taussig, fue rechazado en su solicitud de ingreso a la Universidad de Princeton, aduciéndose la escasa relevancia científica de su obra (1991 43). Como se verá luego, el "ethos posmoderno" que Reynoso cree ver como nota distintiva de los estudios culturales, descalifica ya de entrada cualquier pretensión de cientificidad.

${ }^{3}$ El "case study" que utiliza Reynoso para ejemplificar este eclecticismo es el del antropólogo argentino Néstor García Canclini. Este autor piensa, como los demás “culturistas”, que alguien hace ciencia simplemente cuando toma prestado un concepto y lo aplica a cualquier fenómeno cultural. Antes que un verdadero científico social, Canclini es una especie de periodista cultural con gran olfato para detectar el Zeitgest, algo así como un Lipovetsky latinoamericano. Para Reynoso, la carrera meteórica de Canclini demuestra claramente que el éxito de los estudios culturales no se debe a la calidad científica de sus aportes, sino al oportunismo político de sus practicantes. García Canclini se ha plegado siempre con gran habilidad a las modas teóricas: antes el marxismo y la sociología de la cultura, luego la posmodernidad, el multiculturalismo y la globalización. En palabras de Reynoso: "no creo que sea una interpretación abusiva considerar la carrera de Canclini como un esfuerzo continuado y alerta de suscribir siempre a la última moda intelectual que gana los titulares, y como la manifestación más visible de una escala de valores [anticientífica] en la cual el pragmatismo siempre cotiza más alto y se ejecuta con mayor exactitud que la metodología” (2000 246).
} 
Parece evidente que el juicio que Reynoso pasa sobre los estudios culturales se funda en un modelo de ciencia que, desde Platón hasta Luhman, pasando por Descartes, Husserl y Durkheim, plantea que la cientificidad del conocimiento se obtiene solamente si existe una "ruptura epistemológica" con la opinión, con el sentido común y con todo tipo de nociones "precientíficas”. Este modelo de la representación, que Max Horkheimer bautizara con el nombre de "teoría tradicional”, señala básicamente que a mayor distancia del sentido común, mayor es la posibilidad de crear teóricamente al objeto y de relativizar al máximo los prejuicios subjetivos del científico, incluyendo, claro está, sus valoraciones políticas y morales. Esta eliminación de los elementos subjetivos del conocimiento viene garantizada por un método incontaminado por lo social, que se funda en las matemáticas y la lógica. No es extraño, entonces, que nuestro autor reproche a los estudios culturales - y a toda forma de posmodernismo en general- por asumir una actitud "populista", es decir por su sospechosa proximidad con el sentido común. ${ }^{4}$ Reynoso se pliega de este modo al paradigma hegemónico de cientificidad desplegado por la modernidad: mientras no exista una distancia frente a los saberes que en el mundo de la vida se presentan como “evidentes”, no será posible la emergencia del conocimiento científico.

\section{El fantasma del diablo Se toma la academia}

¿Qué decir frente a los argumentos de Reynoso? En primer lugar es necesario reconocer que muchas de sus críticas, en especial aquellas que apuntan hacia las prácticas académicas y pedagógicas de los estudios culturales, dan certeramente en el blanco. Es cierto, por ejemplo, que muchos de los cultivadores de los Estudios Culturales han adoptado una actitud demasiado "light” frente la rigurosidad teórica de sus planteamientos. Mi opinión es que la ligereza conceptual que en cierto sentido se apoderó de la producción intelectual en el campo de los estudios culturales, tiene que ver con el "tránsito" que hicieron estos desde Europa hacia Estados Unidos durante la década de los ochenta. Mientras que en Inglaterra los estudios culturales se encontraban anclados en facultades de ciencias sociales, en Estados Unidos su anclaje institucional se realizó por lo general en facultades de letras y humanidades. Esto desencadenó varios fenómenos paralelos:

a) Los Estudios Culturales norteamericanos se desligaron paulatinamente de las ciencias sociales y comenzaron a adoptar metodologías más ligeras, pertenecientes a la tradición humanística de los estudios literarios y la filosofía. Esto explica su distancia frente al marxismo y al estructuralismo de corte althusseriano, y también su acercamiento a pensadores como Derrida, Lyotard, Deleuze y Baudrillard. Con otras palabras: en Estados Unidos los Estudios Culturales se empiezan a distanciar del rigor analítico propio de las ciencias sociales y adquieren un perfil más "textualista”, que no se interesa demasiado por el control empírico y metodológico de sus afirmaciones.

\footnotetext{
${ }^{4}$ Refiriéndose a los estudios culturales escribe Reynoso: "La verdad es que la estructura de este aparato [teórico] es ecléctica, una vez más proclive al sentido común, y que no está muy claro si existe o no un plan orgánico de hipótesis a demostrar apoyándose en él” (93-94; el subrayado es mío). Y en otro lugar: "Diversos críticos han llamado la atención sobre la estrecha convivencia que los estudios culturales, más allá de toda su jerga, mantienen con el sentido común” (98).
} 
b) Esta presencia creciente de metodologías “light” en los currículos de prestigiosos departamentos de letras, vinculó rápidamente a los Estudios Culturales con un proceso de "carrerismo académico". Cada vez eran más los profesores y estudiantes que veían en los estudios culturales una oportunidad para ascender rápidamente en la jerarquía académica. El manejo de temas sin demasiada profundidad metodológica pero que gozaban de gran prestigio internacional — por ser reputados como pertenecientes a la "vanguardia teórica”hizo que proliferaran las publicaciones sin sustancia. Basta echar una mirada a la sección “Cultural Studies” en cualquier librería mayor de los Estados Unidos para darse cuenta de que un gran porcentaje de las publicaciones carecen de rigurosidad metodológica.

c) A la ligereza metodológica y el carrerismo académico se une la aureola política con que venían revestidos los estudios culturales. Esta situación provoca no sólo la romantización sino también la banalización de los objetos de estudio. Para un estudiante de doctorado bastaba, por ejemplo, con encontrar un caso cualquiera que pudiera encasillarse como "sujeto subalterno" o como "discurso de resistencia” para tener ya un buen tema de tesis. Entre más abyecto fuese el sujeto estudiado, más interesante la investigación y más cercana la anhelada meta del “tenure track”. ¡Si un solo sujeto pudiese combinar la característica de ser pobre, indio, mujer, inmigrante, chamán, ecologista, bisexual, maquilador, literato y exprisionero político torturado, tanto mejor! Al fin de cuentas, estudios de caso como el de Gloria Anzaldúa no abundan por Estados Unidos. Habrá que continuar esta búsqueda perversa en el "tercer mundo", vista ahora por la academia gringa como una región que, por fortuna, exporta hacia el centro materias primas para sus tesis de doctorado.

A continuación, y de manera breve, examinaré dos de los puntos en que también acierta - por lo menos en parte— - la crítica de Reynoso a los estudios culturales: 1) su falta de reflexividad, es decir, su ligereza epistemológica y 2) su falso carácter antidisciplinario. Este examen tendrá un carácter diagnóstico, ya que su aspecto propiamente terapéutico será desarrollado en la próxima sección.

1) Los estudios culturales, afirma Reynoso, se han limitado a tomar prestados los temas, métodos y objetos de las disciplinas, sin investigar de manera crítica las condiciones de posibilidad a partir de las cuales las disciplinas construyeron esos temas, métodos y objetos (53). Esta crítica de la ligereza epistemológica de los Estudios Culturales complementa la ya mencionada de su ligereza metodológica. Basta observar los programas académicos de estudios culturales ofrecidos por distintas universidades para darse cuenta que en muy pocos — si es que en alguno— se incluye la asignatura "Epistemología de las Ciencias Sociales". Esto explica en parte por qué mucho de lo que se produce en el campo utiliza ingenuamente conceptos e instrumentos analíticos que simplemente "toman” de algún lado, como si crecieran espontáneamente de los árboles, sin establecer previamente su genealogía. El resultado de estos préstamos categoriales irreflexivos es obviamente la contradicción patente entre lo que los Estudios Culturales dicen y lo que los Estudios Culturales hacen. Dicen entender que la ciencia social es un producto histórico y que sus categorías de análisis se anclan en dispositivos de producción social; pero al hacer uso de estos conceptos como quien utiliza un instrumento complejo sin conocer para qué fue construido, los Estudios Culturales demuestran una gran ceguera epistemológica frente a la génesis de su propia práctica teórica y terminan siendo una nueva forma de teoría 
tradicional. Más adelante veremos que, por fortuna, muchos de los trabajos realizados en el campo de los estudios culturales han logrado superar esta ceguera y convertirse en lo que Horkheimer denominase "teoría crítica”.

2) Reynoso se queja con razón de que los estudios culturales han elevado falsamente una pretensión antidisciplinaria. Es cierto, como veremos luego, que los Estudios Culturales nos han permitido comprender fenómenos y relaciones que no eran accesibles a través de las disciplinas existentes, contribuyendo con ello a "indisciplinar" las ciencias sociales. Pero otra cosa muy distinta es afirmar que los Estudios Culturales son una “superación” de las disciplinas y que éstas se encuentran a punto de desaparecer, como si fuesen arrastradas por la necesidad ciega de la historia. Algunos han llegado a decir incluso que las disciplinas son "campos de trabajo forzado" y que los estudios culturales son una especie de "actividad liberadora” que rescatará a los científicos sociales de aquellas "prisiones epistemológicas” en las que se encontraban encerrados (85). Todas estas afirmaciones revelan nuevamente una contradicción interna de los estudios culturales. Dicen estar en la capacidad de analizar críticamente los dispositivos de poder, pero al asumir una actitud decididamente antiinstitucional, desconocen una de las lecciones básicas que hemos aprendido de Althusser, Foucault y Bourdieu: las instituciones académicas, incluyendo aquí las disciplinas, son “campos” en los que se libran importantes luchas (políticas) por el control de los significados. Por esta razón, el anarquismo institucional del que hacen alarde ciertos practicantes de los Estudios Culturales no es tan sólo una actitud infantil, sino que también es una malísima estrategia política.

\section{El diablo No ES COMO LO PINTAN}

En esta última sección trataré de mostrar que, a pesar de sus deficiencias políticas, académicas y pedagógicas, los estudios culturales sí han contribuido positivamente al desafío contemporáneo de “abrir las ciencias sociales” reconocido por la Comisión Gulbenkian (Wallerstein 1996). Y lo han hecho precisamente allí donde Reynoso les niega toda pertinencia y creatividad: en el ámbito metodológico y epistemológico. Argumentaré que estos desafíos se dirigen principalmente hacia el modelo de la "teoría tradicional” con el que trabajaban las ciencias sociales desde el siglo xix, y en el cual se ubica también la obra del antropólogo argentino. Esto explica la actitud defensiva que asume Reynoso a todo lo largo de su libro. Siente que la identidad de su disciplina de origen, la antropología, se encuentra gravemente amenazada, pero lejos de preguntarse cuáles son los desafíos históricos a los que tanto ella como las demás ciencias sociales se encuentran enfrentadas, prefiere buscar un enemigo de paja, los estudios culturales, e “inventarse el diablo" con ellos.

Comenzaré con una reflexión general que permita apreciar cuáles son algunos de los desafíos actuales que enfrentan las ciencias sociales contemporáneas, qué implicaciones tiene esto para la reestructuración de sus paradigmas teóricos, y cuál ha sido el aporte de los estudios culturales en este proceso de reestructuración. La pregunta inicial será: ¿cómo han cambiado los objetos de estudio de las ciencias sociales y en qué consiste el valor explicativo de los “nuevos” objetos creados por ellas en las últimas décadas del siglo xx? ¿Qué cambios sociales a nivel planetario han influido el hecho de que un objeto de 
conocimiento llamado "la cultura” adquiera hoy un nuevo valor o “significación” al interior de la comunidad científica?

Digamos primero que las estructuras de producción y reproducción que caracterizan la sociedad global en la que vivimos se alejan radicalmente de aquellas que habían teorizado cientistas sociales como Smith, Ricardo, Marx, Keynes y Prebisch. El capitalismo industrial o fordista de los siglos xIx y primera mitad del xx ha sido reemplazado por un capitalismo posindustrial, en el que las categorías de análisis provenientes de la economía clásica han perdido su poder explicativo. Esto se debe básicamente a dos factores:

1) Los estados nacionales han dejado de ser los espacios de concentración de la hegemonía política y cultural. No son ahora los estados territoriales quienes jalonan la producción, sino corporaciones transnacionales que se pasean por el globo sin estar atadas a ningún territorio, cultura o nación en particular. El capital ha venido perdiendo sus connotaciones nacionales (capital inglés, japonés, alemán, norteamericano) para subordinarse cada vez más a formas propiamente "globales" de intercambio. El aparato estatal se ha reconfigurado de acuerdo a la exigencia mundial de los mercados y siguiendo los lineamientos trazados por corporaciones supranacionales (como el Banco Mundial, el Fondo Monetario Internacional y la Organización Mundial del Comercio). Lo que a comienzos del siglo xxi se impone como fuerza configuradora de lo social es un conjunto de relaciones posnacionales y postradicionales que han sido potenciadas por las nuevas tecnologías de la información.

2) La industria cultural, como ya lo mostraran Horkheimer y Adorno, se ha convertido en una de las principales — si no la más importante_- "fuerza de producción" del capitalismo contemporáneo. Esto significa que lo que se produce y mercantiliza hoy en día no es tanto naturaleza convertida en "valor de cambio", como pensara Marx, sino información y entretenimiento. Hemos pasado de la producción de artículos empaquetados al empaquetamiento de informaciones articuladas como mercancía. La producción y reproducción del capital dependen ahora del control que ejercen las corporaciones sobre las imágenes y las representaciones.

Esto significa que la "cultura” ha dejado de ser exclusivamente un conjunto de valores, costumbres y normas de convivencia ligadas a una tradición particular, a una lengua y a un territorio. En tiempos del capitalismo avanzado, la cultura se ha destradicionalizado y desterritorializado, es decir, se ha convertido en un repertorio de signos y símbolos producidos técnicamente (de acuerdo a intereses particulares) y difundidos planetariamente por los medios de información. Este universo simbólico, así desligado de la tradición, empieza a definir el modo en que millones de personas en todo el globo sienten, piensan, desean e imaginan. Querámoslo o no, la globalización nos ha conectado vitalmente con territorios postradicionales en donde las identidades personales o colectivas no se encuentran referidas a pertenencias de lengua, sangre o nación, pues ya no se estructuran desde la inmanencia de las tradiciones, sino desde la interacción de la cultura con la dinámica transnacional de los mercados. Con una palabra: desde mediados del siglo xx estamos asistiendo a un cambio cualitativo en el "estatuto" de la cultura.

¿Qué implicaciones tiene todo lo anterior para una re-definición de la “cultura” como objeto de conocimiento científico? 
1) Que a pesar de las quejas de Reynoso, la cultura deja de ser "propiedad” de la Antropología. Dentro de la división del trabajo disciplinario en ciencias sociales, establecida desde el siglo XIx, la sociología era la encargada de estudiar las sociedades "modernas", mientras que la antropología realizaba el estudio de las sociedades “tradicionales”. El objeto de la primera era la “civilización”, mientras que el de la segunda era la "cultura”. Pero la globalización parece haber terminado definitivamente con estas divisiones. Aquellas poblaciones sin contacto alguno con la modernidad - y cuya observación por parte de los europeos originó desde el siglo xviII el concepto "tradicional” de cultura — han desaparecido prácticamente de la faz de la tierra. Mantener una definición de la antropología como disciplina que trata de valores, tradiciones y costumbres premodernas significaría convertir la materia en una variante de los estudios museísticos, y al antropólogo en una especie de guardián del “patrimonio histórico” de la humanidad. Si quiere sobrevivir y redefinirse como disciplina científica, la antropología tendrá que incursionar (metodológica y temáticamente) en áreas que antes no eran de su competencia.

2) Que la cultura deja de ser vista como un “reflejo” de las estructuras materiales de la sociedad, tal como lo planteaban tradicionalmente la sociología y la economía. Tanto los sociólogos de orientación liberal, como aquellos de orientación marxista, miraron siempre la cultura como un epifenómeno de la vida económica de la sociedad. Pero en el momento en que la reproducción del capital adquiere rasgos decididamente "culturales" - como hemos visto anteriormente- , se le impone a la sociología y a la economía entrar en dominios que antes se consideraban exclusivos de otras disciplinas.

3) Que la cultura deja de ser propiedad de los estudios humanísticos (filosofía, literatura, artes). Desde el renacimiento, y trazando sus orígenes en la tradición griega de la Paideia, las humanidades se concentraron en el estudio y la interpretación rigurosa de textos que pudieran educar (Bildung) o “cultivar” el espíritu del hombre. Pero en el momento en que la producción cultural se masifica por el impacto de la globalización, entonces se hace necesario investigar no solamente los contenidos de la llamada cultura “alta” (las "grandes obras” de la literatura, de la filosofía o de las artes plásticas, donde supuestamente se hallaría contenida la "cultura” y el pensamiento del hombre en sentido estricto), sino muy especialmente la cultura llamada “popular”. Esta última, a su vez, deja de ser patrimonio exclusivo de los folcloristas o de los antropólogos urbanos. Las humanidades se ven compelidas de este modo a entrar en diálogo con otros campos de estudio, si es que desean evitar el riesgo de convertirse en defensoras y promotoras de una cultura de elites (que, entre otras cosas, también ha dejado de serlo).

Es en este punto que el campo emergente de los estudios culturales aparece como espacio de articulación entre las disciplinas. No se trata de una nueva disciplina que viene a reemplazar lo que hacían antes las disciplinas tradicionales de las ciencias sociales, sino de un área común de conocimiento que contribuye a redefinir los límites de esas disciplinas. La novedad de este campo emergente puede apreciarse tanto a nivel metodológico y epistemológico, como a nivel de contenidos temáticos:

1) A nivel metodológico $-\mathrm{y}$ a pesar del auge que han tenido ciertas tendencias culturalistas, populistas o posmodernistas en los últimos años-, los estudios culturales han contribuido a superar la dicotomía entre el objetivismo y el subjetivismo (es decir, entre las tendencias nomotéticas y las ideográficas de las ciencias sociales). La cultura se 
ha convertido en la pinza que vincula las estructuras sociales con los sujetos que la producen y reproducen. Plantear la relación dialéctica entre sujeto y estructura es, pues, el principal aporte metodológico de los estudios culturales.

2) A nivel epistemológico, los estudios culturales se inscriben en lo que Boaventura de Sousa Santos ha llamado la "doble ruptura epistemológica” de las ciencias sociales. Si la "primera ruptura” (siglos XIx y xx) se realizó frente al sentido común y adoptando el modelo propagado por las ciencias naturales (alejamiento de las "nociones precientíficas" y creación de una distancia con respecto al "objeto"), ${ }^{5}$ la "segunda ruptura" —que se realiza actualmente - apunta hacia una eliminación de la distancia frente al sentido común. Lo cual significa que las ciencias sociales contemporáneas se enfrentan al desafío de acercarse hacia otras formas de producción de conocimientos, pero no para convertirlas en "objeto de estudio", es decir para "representarlas" — como hacía la teoría tradicional— sino para comunicarse con ellas. Los estudios culturales son un punto de avanzada de las ciencias sociales hacia el reconocimiento de otras formas (locales) de conocimiento y para la promoción de un nuevo sentido común (una nueva racionalidad práctica) en el que participen todas las comunidades interpretativas.

3) A nivel de contenidos temáticos, la cultura que los estudios culturales "crean” como objeto de conocimiento no es la misma que habían creado anteriormente la antropología, la sociología, la economía ni las humanidades. Es decir que no es el conjunto “orgánico” de valores, lenguajes, mitos y creencias tradicionales (concepto “antropológico” de cultura), ni tampoco el efecto ideológico de los procesos que ocurren en la base material de la sociedad (concepto "economicista” de cultura), y mucho menos la objetivación del espíritu de los grandes creadores y pensadores (concepto "humanista” de cultura). La cultura que "estudian" los estudios culturales tiene menos que ver con los artefactos culturales en sí mismos (textos, obras de arte, mitos, valores, costumbres, etc.) que con los procesos sociales de producción, distribución y recepción de esos artefactos. Es decir, los estudios culturales toman como objeto de análisis los dispositivos a partir de los cuales se producen, distribuyen y consumen toda una serie de imaginarios que motivan la acción (política, económica, científica, social) del hombre en tiempos de globalización. Al mismo tiempo, los estudios culturales privilegian el modo en que los actores sociales mismos se apropian de estos imaginarios y los integran a formas locales de conocimiento.

El informe de la comisión Gulbenkian ha destacado el papel que los estudios culturales están cumpliendo en la actual reestructuración de las ciencias sociales. De acuerdo al informe, los estudios culturales han impulsado un "giro hermenéutico" que afecta positivamente a las disciplinas tradicionales y a los espacios institucionales en donde éstas funcionan. Los estudios culturales le han enseñado a las disciplinas que la construcción de los conceptos es inductiva y empieza con el análisis de lo “local”. De la antropología han tomado su mejor herencia, la mística del trabajo de campo, para mostrar que los modelos teóricos se construyen a partir de la inmersión del investigador en las

\footnotetext{
${ }^{5}$ La distancia frente al objeto obedece al “paradigma de la representación”. La ciencia moderna se distancia del sentido común (visto como “doxa”) para aislar metodológicamente a un “otro de la representación” llamado “objeto”, creando una distancia frente a él. Mientras mayor es la distancia, más objetivo es el conocimiento.
} 
prácticas de los actores concretos. Mientras que los paradigmas decimonónicos de las ciencias sociales establecían una contraposición entre lo próximo y lo objetivo (a mayor distancia frente al objeto mayor objetividad), los estudios culturales invierten la relación y privilegian el aspecto ético-práctico del conocimiento sobre su aspecto puramente cognitivo. Entre más próxima sea la interacción del investigador con los saberes producidos localmente por los actores sociales mismos, más pertinente, desde un punto de vista práctico, es el conocimiento resultante.

Debería quedar claro que los estudios culturales no son una nueva disciplina, sino un área común de conocimiento que, sin embargo, no constituye un simple agregado de contenidos y metodologías ya planteados por las disciplinas tradicionales. Por el contrario, los estudios culturales han generado un positivo "efecto de retorno" sobre el trabajo de estas disciplinas, tanto desde el punto de vista metodológico como temático. Al ser una práctica teórica alternativa al modelo de la teoría tradicional desarrollado durante los siglos XIX y xx, los estudios culturales subordinan el know-how técnico al know-how práctico y ético del conocimiento. Por ello han contribuido, como indica el informe de la comisión Gulbenkian, a crear puentes entre las diferentes disciplinas de las ciencias sociales, y entre éstas y los saberes locales.

\section{Abogado del diablo}

A partir de estas reflexiones, ¿qué diremos entonces al libro de Reynoso?

a) Lo que está en “decadencia” no son los Estudios Culturales como tales, sino el modelo de "teoría tradicional” desde el que argumenta Reynoso.

b) El paso de la teoría tradicional a la teoría crítica no es prerrogativa de los estudios culturales. Ellos no constituyen la "superación dialéctica” de las disciplinas tradicionales ni tampoco son la nueva "vanguardia” de las ciencias sociales

c) Los Estudios Culturales no son una "antidisciplina libre” sino un área común de conocimiento que ha contribuido a una retroalimentación de las disciplinas, esto es, a una reestructuración de sus paradigmas tradicionales.

d) La transdisciplinariedad de los Estudios Culturales dinamiza el proceso de "segunda ruptura epistemológica”, que es el desafío actual al que se enfrentan las ciencias sociales. La universidad no es ciertamente el único ni el más importante lugar de “aproximación” del conocimiento científico con el sentido común, pero es ciertamente un lugar importante.

e) La institucionalización de los Estudios Culturales no conlleva necesariamente su despolitización. Siendo la universidad un importante "aparato" de producción de conocimientos, su función al interior de las estructuras académicas es muy importante. Los Estudios Culturales pueden contribuir a que la universidad se convierta en un espacio de convergencia entre diferentes comunidades interpretativas.

f) El gran peligro al que se enfrentan los Estudios Culturales es la pérdida de su dimensión crítica, esto es, su olvido de que el capitalismo en tiempos de globalización adquiere una dimensión decididamente simbólica. Retomando el legado de Marx, el reto de los Estudios Culturales es contribuir a que las ciencias sociales se vinculen con una crítica de la economía política de la cultura. 
BiBLIOGRAFÍA

Reynoso, Carlos. Apogeo y decadencia de los estudios culturales. Barcelona: Gedisa, 2000.

(Comp.). El surgimiento de la antropología posmoderna. Barcelona: Gedisa, 1991.

Wallerstein, Inmanuel (Coord.). Abrir las ciencias sociales. Informe de la Comisión Gulbenkian para la reestructuracion de las ciencias sociales. México: Siglo XXI, 1996. 